\title{
Formed in the Image of God: The Theological Status of Neanderthals
}

\author{
Megan Stueve
}

\begin{abstract}
A thorough examination of the various theological interpretations of imago Dei shows that Homo sapiens are not the only species to be created in the image of God. While maintaining their uniqueness in the eyes of the Lord, Homo sapiens also share this gift with another species, Homo neanderthalensis. The archaeological record proves that Neanderthals qualify for imago Dei under each of the four main interpretations of the biblical term. Based on their rationality and adaptive nature, their compassion through use of medicine, their social networking and their symbolic use of art, it can be concluded that Neanderthals were also created in God's image.
\end{abstract}

Being created in the image of God (imago Del) implies that we as humans are special creatures and were created with a unique purpose for life on earth. Most people in the Christian church derive this understanding from reading scripture and assume that it only pertains to our specific species of humans. Yet when other species of Homo are compared to the definitions of imago Dei as described by various theologians throughout the centuries, this assumption simply does not hold true. This study will examine attributes of just one of our cousin species, Homo neanderthalensis, to illustrate the need for a continued discussion of human origins and imago Dei.

There are four main definitions of imago Dei that have been proposed by theologians-substantialistic, functional, relational and eschatological (van Huyssteen 2006). Each of these interpretations will be explained and then applied to anthropological data pertaining to the lives of Neanderthals. The data will show that Neanderthals were a species so similar to contemporaneous Homo sapiens populations in almost every way that they should be included in the discussion of humanity's identity as made in the image of God.

\section{Substantialistic}

The substantialistic, or substantive, conception of imago Dei is perhaps the most common and the most prevailing understanding among Christians. As the name suggests, imago Dei here refers to the substance

Megan Stueve has an M.A. in Theological and Cultural Anthropology and is preparing to conduct fieldwork in archaeology. Author email: mstueve@eastern.edu. of the human being. When God created humanity in the image, human beings were endowed with characteristics that make us like God (Hall 1986:89). Of course, this is not intended to mean a physical likeness to the Creator, who is spirit, but rather a mental or intellectual quality. Human mental abilities have commonly been narrowed to rationality and freewill, deduced by working backwards from what humans possess that animals do not. Human rationality, or intellect, has been defined as the ability to conceptualize in a reflective manner and be transformed as a result (Deane-Drummond 2012:936). Freedom and freewill are included, as animals are constrained by biological boundaries (instinct) that human beings are capable of surpassing (e.g. visualizing somewhere you have never been). It must be noted that in this interpretation humanity's freewill and rationality cannot be lost or gained; instead, they have been bestowed upon humanity by the Creator. Thus, human beings are unique in the image of God by virtue of their innate mental capabilities.

An abundance of data exists that is capable of documenting the rationality and freewill associated with Homo neanderthalensis, yet the focus here will remain on mortuary data as it is plentiful. Throughout the existence of the species, Neanderthals utilized a variety of different techniques regarding disposal of the deceased. Instances of Cronos compulsions-bodily modification associated with defleshing of the bonesexist early on in Neanderthal mortuary history at sites such as Krapina, Croatia dated to approximately 130KYA. Similar evidence can be found in Herto, Ethiopia documenting that Homo sapiens were also practicing Cronos compulsions at this time. The remains found in both locations display shallow repetitive cut marks, which indicate a processing of the 
bones rather than hasty defleshing for the purposes of cannibalism. Such processing is not accidental or the result of natural forces; instead it is the result of gentle motions, suggesting attention and care were involved.

The site of Amud Cave, Israel demonstrates the existence of another disposal method, funerary caching, among Neanderthal groups (Hovers, Kimbel and Rak 2000). Dating to approximately 50KYA (Valladas et al. 1999), the remains of an infant were found neatly placed inside a niche in a cave wall. Atop the bones of Amud 7 was the maxilla of a red deer, thought to be an intentional grave good. A study was performed to determine if the remains could have naturally accumulated as they were found; however, it was determined that the cave sloped away from the remains, not towards them, which would have been necessary for natural accumulation (Hovers, Kimbel and Rak 2000). Therefore, placement of the infant within the niche and in association with the red deer maxilla was intentional, signifying the intelligence and deliberateness Neanderthals displayed in their burial rituals at this time. Homo sapiens were also practicing funerary caching around 50KYA, as evidenced by remains found at Taramsa Hill, Egypt (Vermeersch et al. 1998).

Homo neanderthalensis was also capable of a wider variety of mortuary practices. Simple inhumation, where remains are placed in a shallow pit, exists throughout the known locations of Neanderthal cave occupation. From Israel to France and spanning almost 100,000 years, Neanderthal populations buried their deceased in pits in the ground. Variations exist in cardinal direction and location within the cave, however the extent of this practice indicates its preference in such populations. The site of La Ferrassie, dated to 7468KYA (Klein 1999:427), represents a site of multiple simple inhumations; as many as eight sets of Neanderthal remains were found in small pits spread throughout the cave. Several were located in groups suggesting that they were buried in their respective pits near in time to one another. The interring of remains at this site repeatedly over several thousand years indicates that it held some significance for Neanderthal populations living in the area at this time.

Some Neanderthal populations began experimenting with more formal and elaborate burials, as evidenced by Regourdou Cave, France, 65-55KYA (Pettitt 2011:112-114). An intriguing site, the remains of a Neanderthal of unknown gender were found in a pit lined with small flat stones. This unique paving of the pit has not been discovered in any other Neanderthal burials. Several long bones of a cave bear were placed inside the pit alongside the Neanderthal remains; the pit was covered over with a large stone slab. Located on one side of the pit was a second stone slab, placed vertically, that acted as a wall which separated these remains from that of a brown bear (Pettitt 2011:
112-113), a third stone slab enclosed these remains as well. All was covered over with stones decreasing in size, followed by sand, which was then burned in a fashion similar to a funeral pyre. Regourdou is interesting mainly because it displays some of the diversity of Neanderthal mortuary techniques.

This variety in Neanderthal mortuary activity is not related to regional differences in populations. Each of these techniques can be seen throughout the expanses of occupational areas. The variability that exists in mortuary activity is instead the direct result of the changing climate. As glacial and interglacial periods come and go, burial techniques must be modified. During periods of glaciation when the ground is too difficult to break, disposal is relegated to above ground methods only. It is here that instances of Cronos compulsion and funerary caching become prevalent. However, during interglacial periods of warmth, ground burials such as simple inhumation and formal burial abound. It is clear that ground burials are the preferred method of disposal of the deceased, however, there is desire to provide a type of burial during periods of extreme cold, hence the above ground methods.

Early on, both Homo sapiens and Homo neanderthalensis were practicing Cronos compulsions as a way to dispose of their dead. As the glacial period turned into interglacial, burial practices of both species gave way to simple ground burials. Thousands of years later when the earth shifted back into a glacial period, above ground methods were needed in order to continue with mortuary practices. With Cronos compulsions long forgotten, funerary caching arose. During warm interstitials and periods of seasonal warmth there is a return to simple inhumation and formal burials, which return fully in our current interglacial period, indicating the overall preference for this methodology. Thus, Neanderthals displayed their cognitive abilities by adapting their mortuary patterns to the changing climate. This is not merely a biological response, but a cognitive development. The fact that both Homo sapiens and Homo neanderthalensis display similar burial patterns at similar times indicates their common rational abilities as they relate to environmental adaptations and burial traditions. Since these adaptations could not have been the result of contact with one another, they reflect independent ingenuity.

Many variations exist in the mortuary patterns of Homo neanderthalensis, just as there are variations in the funerary activity of Homo sapiens. Often, Neanderthals are performing these activities first, before Homo sapiens, in evolutionary history. There is evidence of grave goods in Neanderthal burials tens of thousands of years before Homo sapiens, and the same is true of the appearance of multiple burials. The intellect that Neanderthals possessed in order to 
accomplish such intricate burials is undeniable. They practiced a variety of funerary activities, showcasing their ability to adapt their techniques to environmental surroundings and to the changing climate. The introduction of grave goods and elaborate burial structures, such as that at Regourdou, indicate that such adaptations were not merely due to environmental constraints but also to a cognitive understanding of the significance of life and death. Since archaic Homo sapiens, as contemporaries of the Neanderthals, were also able to adjust their mortuary practices to the changing environment and perform a variety of mortuary methods, it is apparent that the two species were incredibly similar to one another in terms of their rational abilities, the key aspect of the substantialistic interpretation of imago Dei.

\section{Functional}

While the substantialistic interpretation of imago Dei is still the most prevalent, it has the drawback of focusing so heavily on intellectual abilities that it seemingly ignores the body entirely. The functional approach was introduced to balance the mind and the body in our understanding of the image of God in humankind. It also emphasized what humanity is called to do in terms of behavior (van Huyssteen 2006:134). In this understanding, humanity has been selected to be stewards of God's creation, and has been given authority to claim dominion in God's name. As God's representatives on earth, humans are to enact order in nature and rule over every other living creature. This interpretation is validated in the Genesis imago texts of stewardship and dominion (Genesis 1:26-27) and paints humanity as the enforcers of God's rule over the earth. Middleton takes this even further, stating that humanity is seen as royal or even godlike among the other creatures of the world; hence this view is sometimes called the royal-functional interpretation of imago Dei (2005:28). It is with this approach that the "cultural mandate" arises, pushing humans towards culturemaking activities such as "city-building, alchemy, politics, scholarship, [and] the arts" (Middleton 2005:29).

Although there is no archaeological evidence to prove that Neanderthals were capable of city-building or other advancements that Homo sapiens have only known in the last few millennia, there is evidence to show that Neanderthals were capable of stewardship and dominion over the earth. Dominion in the theological sense has multiple parts; it is not merely tending to the earth itself, but also involves protection of animals and, more importantly, concern for each other. Neanderthals demonstrated this concern for one another in their treatment of their own injured members. As a robust species, Neanderthals had denser bones than Homo sapiens, but this did not prevent them from injuring themselves regularly with "few escaping life with no clear evidence of injuries" (Spikins 2015:222). Although many of the injuries found in various Neanderthal skeletons are not limiting, there are a few that most certainly would have required the care of others to survive.

Affectionately known as Nandy, the remains of a 4050-year old Neanderthal male were found in Shanidar Cave, Iraq (Trinkaus 1983). Shanidar 1, as he is formally named, lived between 50-40KYA during a period of frequent tectonic activity in the Middle East. Nandy was an elderly man, his age equivalent to 80 years old in modern Homo sapiens, yet he survived a plethora of egregious injuries. It is unknown if all of these injuries were sustained in one incident or if they were spread out throughout his lifetime; however, they all show antemortem healing, indicating that none were fatal. When Nandy was located, his lower right arm was missing from the remains. A careful examination concluded that he was either born without it or it had been amputated at some point during his life. The right upper limb bones displayed significant shrinkage as a result of disuse, including the humerus, scapula and clavicle. There was evidence of a bone infection in these areas, which would have required constant medical treatment in order to overcome. In addition to the loss of the lower right arm, the right leg also showed signs of damage. The tibia was concave and there was extensive trauma to the foot. This would have made it very difficult for Nandy to walk. If he could walk at all, he would have had a very heavy limp and certainly required a crutch.

Overcoming the injuries to the right side of his body, Nandy also survived a "crushing fracture to the lateral side of the left orbit” (Trinkaus 1983:409), almost certainly leaving him blind in his left eye. Nandy most likely also suffered from brain damage as a result. Leaning heavily on his left leg, with only a left hand, Nandy had no sight on his left side. In addition to the medicine needed to cure his injuries and subsequent bone infections, Nandy needed help in almost every activity of his daily life. Unable to hunt, cook or even protect himself from predators, Nandy required the care of others in his community in order to live into old age. Unfortunately, Nandy did not die peacefully in his old age; instead he had the unlucky fate to be crushed when the ceiling of his cave collapsed during an earthquake. In life, he would have had little to offer the group of Neanderthals that he lived with, but they took compassion on him and cared for his injuries until the day of his death.

Another elderly Neanderthal found in the same cave and termed Shanidar 3 also suffered from injuries that required attention from other individuals. The most notable injury occurred between his eighth and 
ninth left ribs. A penetrating injury to this location surely would have caused death quickly, however the paleopathological evidence shows antemortem healing of up to several weeks. As Shanidar 3 lay dying from his injury, he was provided enough food and protection from predators to live several more weeks before ultimately succumbing to his injuries. Trinkaus has established that his injury could not have been selfinflicted or from a natural phenomenon; instead the parsimonious explanation is that a right-handed individual intentionally or accidentally stabbed Shanidar 3 while they were facing each other (Trinkaus 1983:414). In any case, Shanidar 3 would not have survived more than a few days without medicinal care, food and protection from others in his community.

This kind of stewardship does not exist only in the Middle Eastern Neanderthal populations, but can also be demonstrated as far away as France (Pettitt 2011: 110). In a cave in La Chapelle-aux-Saints, another 40year-old Neanderthal was found with injuries that would have required attention and care from others in his group. Called the "Old Man" of La Chapelle-auxSaints, LCS1 had extensive resorption of the bone on the right side of the mandible; this was caused by antemortem loss of teeth. With only five upper and five lower teeth still in occlusion on the left side of the mouth, LCS1 would have had a difficult time chewing his food. While not entirely indicative that he required help to survive, LCS1 would have needed to turn most foods into a soft, mush-like consistency in order to maintain adequate nutrient levels. The loss of teeth on the right side was most likely caused by a tumor or abscess growing inside the mouth. This might have caused the teeth to decay and fall out if left untreated, or they might have been manually pulled in order to reach and drain the abscess.

In addition, LCS1 had severe degenerative joint disease of his cervical and thoracic vertebrae, meaning that any movement would have been tedious and excruciating. The left hip also displays resorption of the bone, making walking extremely difficult. The Old Man would not have been able to fend off an attack from predators or even walk far enough to gather berries to eat. In order to survive into old age, LCS1 would have required aid and protection from his companions.

Although it is not possible to determine from the archaeological record if Neanderthals stewarded other aspects of the created order, it is clear that they cared for one another as the Creator intended. Much in the same way that Homo sapiens tend to one another, Homo neanderthalensis also cared for those in their social groupings. They were capable of medicinal technology that cured infections and protecting the weak from predation. Such data provides evidence for compassionate care in Neanderthal populations. This compassion is part of the stewardship that allows Neanderthals to be classified as created in the image of God under the functional understanding of imago Dei.

\section{Relational}

In the functional interpretation, dominion over the created order can often be misinterpreted by the reader as domination, leading to an exploitation of resources, the opposite of its intent. The relational interpretation, however, still incorporates the mind and the body in a holistic effort, but focuses on the human ability to enter into and maintain good relationships with God and with others. Humanity is created to be in relationships and it is only through these relationships that human beings are in the image of God. It is remarked that "humans have a natural urge for culture, and therefore for the unlimited, for that which cannot be confined by natural instinct" (van Huyssteen 2006:136). This relates directly to human social nature and depicts humanity's need to interact with others as stemming from the desire to interact with God. As human beings are not capable of physically interacting with the Creator, the constant thirst for attention is only pacified through social relationships with fellow human beings. Therefore, as God would interact with humanity, humanity is imaging God in their relationship with other people (Hall 1986:98).

While it is impossible to know with certainty whether or not Neanderthals had a relationship with the Creator, we do know that they maintained social relationships with one another. Typically, several familial groupings-each group usually consisting of ten to fifteen individuals-would inhabit a cluster of caves near each other. Although a bit on the shy side when it came to strangers, Neanderthals were welcoming of those they knew. The archaeological record shows that they hunted and gathered communally, created stone tools together and provided medicinal care for one another. They feasted and were capable of complex linguistic sounds ranging from speech to song (Mithen 2006). They even made beads for jewelry just like Homo sapiens. All of these activities required social relationships to complete. Both Homo sapiens and Homo neanderthalensis had social ties with others in their communities that exceeded the instinct-based biological ties between herds or packs of animals. This was not solely for protection or to aid in the procurement of food resources. Neanderthal social relationships were not merely for survival, but also for entertainment and leisure. Such relationships allowed Neanderthals to image God under the relational conception of imago Dei. 


\section{Eschatological}

The final interpretation of imago Dei is the eschatological and it revolves around humanity's search for deeper meaning. Again working backwards from what separates humanity from animals, this interpretation focuses on the openness that humanity has towards the world. Whereas animals are bound both physically and mentally to their environments, humankind is capable of an "exocentricity...that points human beings toward a destiny that has not yet been reached" (van Huyssteen 2006:139). It has been proposed that this destiny is the ultimate reunion with the Creator. Much in the same way that the human desire to be with God leads to social relationships in the relational concept of the image, here it allows humans to live beyond ordinary experience. Whereas animals are bound to their environments and their immediate needs such as food and shelter, humans are capable of bringing culture into nature and transforming their surroundings with a larger sense of purpose. While the eschatological interpretation incorporates aspects of the other approaches to imago Dei, it pushes further into the symbolic nature of the human mind and its expression through conceptualizations of the future.

Before they perished, Homo neanderthalensis populations had a developed sense of culture. From stone tools to artwork, Neanderthals had the ability to think forward into the future to create objects with meaning. While certain animals are capable of using tools to procure food, such as the otter using stones to smash open shells or chimpanzees using sticks to obtain termites, these actions only involve one step: find a stone or stick. Neanderthal tool making required finding the right type of stone, imagining and then creating the end product, a multistep process.' This forward thinking enabled them to break off bits of stone until they created a variety of stone tools. In fact, their style is so unique it was given its own name, Mousterian.

Included in the eschatological interpretation of the imago Dei is the ability to think towards the future to a place after death. Homo sapiens were not the only species to do so; we know through the use of grave goods that Neanderthals were also capable of such thinking. If they were merely burying the deceased to protect themselves from hungry predators looking for an easy meal, there would have been no reason to include grave goods. Extensive use of ochre throughout many burial sites indicates that Neanderthals had some symbolic connection to these pigments, most likely involving future use after death. Although there is a debate about whether use of ochre constitutes symbolic activity, the production of artwork certainly settles it.
There are instances of painted art found in a few caves in Spain that can be tied to Neanderthal occupation through tool use (Than 2012). Nearby in France, a Neanderthal created another piece called the Mask of La Roche-Cotard (Marquet and Lorblanchet 2003). A small, flat red stone was chipped until a piece of white bone could slide through to create what looked like eyes in a face. The bone was secured with small pebbles to ensure it would not come loose, indicating that it could not have been the result of natural occurrences. The creation of such a mask requires the ability to think forward toward an end goal and work in steps to achieve the final product. Through use of grave goods and artwork, it is clear that Neanderthals were capable of thinking openly about the world, outside of biological constraints, and transforming nature into culture.

\section{Discussion}

The purpose of this study is not to conclude which of the interpretations of imago Dei is the correct one or to sway the reader into believing one over the other. Instead, it is to show that regardless of which interpretation more closely fits the reader's interpretation of the scriptural phrase, Neanderthals also fulfill those requirements and should therefore be included as humans bearing the image of God. Neanderthals displayed human levels of rationality; they demonstrated compassion and care for one another; they were capable of social relationships; and they understood the search for deeper meaning in both life and death. In fact, Neanderthals displayed these characteristics in the same measure and capacity as contemporaneous Homo sapiens. Some position God's gifting of the imago Dei to humanity after the extinction of Neanderthals, at what is known as the cultural revolution, when the material culture of Homo sapiens seemingly exploded leaving cave art and elaborate burials in its wake. However, archaeological evidence proves that Neanderthals were producing such material culture before the extinction of their species-and before Homo sapiens were producing ittherefore if material culture is what constitutes the image of God then Neanderthals actually anticipated the requirements of imago Dei.

It may be difficult for some to accept Neanderthals as also made in the image of God; after all, it is only natural to think that our species is special. We are the only human species that currently inhabits the earth; therefore when the Bible says that God created humanity in the image, it must refer exclusively to us. This is a common theme throughout theological

\footnotetext{
' Though chimpanzees do strip the leaves from sticks, a rudimentary form of tool making, this is a very small step compared to the complex activities involved in the construction of stone tools by humans, both Homo sapiens and Neanderthals.
} 
discussions of imago Dei: defining ourselves as different from other species. Succinctly put by Hall, "'different' almost invariably implies 'higher', 'nobler', 'loftier', 'better" (1986:90). By constantly placing our species above all others, even those who are so similar to ourselves, we are contributing towards our own destructive nature. This destructive nature is described as "man's tragic destiny: he must desperately justify himself as an object of primary value in the universe; he must stand out, be a hero, make the biggest possible contribution to world life, show that he counts more than anything or anyone else" (Becker 1997:4). Yet analysis of the lives of Homo neanderthalensis and Homo sapiens populations shows a high degree of similarity between the two species in terms of their abilities. In fact, it becomes difficult to locate the line that would declare one superior to the other in the time frame in which they were coexisting. With such similarity, there is little doubt that had Neanderthals survived into the present day interglacial, they would most likely share the same cultural inclinations as modern day Homo sapiens.

There is no doubt that this study will not be received well by all. Most Christians are convinced that the image of God is meant only for Homo sapiens. However, the current interpretations of imago Dei do not support such an argument. In order to maintain the uniqueness of Homo sapiens over Homo neanderthalensis there would need to be an additional interpretation of imago Dei. This new definition would have to rely on some other facet of humanity that does not relate to any of the characteristics explored above. If we are to search for such a new interpretation, we will have to ask ourselves why it is necessary. Are we simply protecting our own pride? If so, then it is not God or Scripture that we are defending, but rather ourselves.

\section{Conclusion}

Each of the aspects of imago Dei presented above can be demonstrated in the archaeological record of Homo neanderthalensis. The rationality that Neanderthals evidenced in conjunction with burial traditions signifies that they fulfill the substantialistic interpretation. The compassion and care for one another that they displayed indicate their attainment of the functional understanding. The relational conception is fulfilled through the social connections they had with one another. Finally, the eschatological approach is proven through their ability to think forward into the future through symbolic artwork. However, Homo sapiens and Homo neanderthalensis are not the only species to display similar attributes; the archaeological record shows that other species of Homo are also capable of some of these actions. This study highlights the necessity for an open dialogue between anthropologists and theologians on the topic of human origins and the image of God.

As Homo sapiens, we still maintain the uniqueness that God created us in the image, yet we share this image with other species of humans that are so similar to ourselves that we are only distinguishable based on anatomical size. Scripture does not state that God chose Homo sapiens to be in the image, but that all humanity was chosen. Our pride and desire for transcendence has blinded us into thinking that we are the only species made in the image of God. But further anthropological research has allowed us to open our eyes and see that Neanderthals are not just our evolutionary cousins, but part of God's plan for humanity as a whole.

\section{References}

Becker, Ernest. 1997 (1973). The denial of death. New York: Free Press Paperbacks.

Deane-Drummond, Celia. 2012. God's image and likeness in humans and other animals: performative soul-making and graced nature. Zygon 47(4): 934-948.

Hall, Douglas John. 1986. Imaging God: dominion as stewardship. Eugene, OR: Wipf and Stock Publishers.

Hovers, Erella, William H. Kimbel, and Yoel Rak. 2000. The Amud 7 skeleton-still a burial. Response to Gargett. Journal of Human Evolution 39:253-260.

Klein, Richard G. 1999 (1989). The human career: human biological and cultural origins. Chicago: The University of Chicago Press.

Marquet, Jean-Claude, and Michel Lorblanchet. 2003. A Neanderthal face? The proto-figurine from La RocheCotard, Langeais (Indre-et-Loire, France). Antiquity 77: 661-670.

Middleton, J. Richard. 2005. The liberating image: the imago Dei in Genesis 1. Grand Rapids, MI: Brazos Press.

Mithen, Steven. 2006. The singing Neanderthals: the origins of music, language, mind and body. Cambridge, MA: Harvard University Press.

Pettitt, Paul. 2011. The Paleolithic origins of human burial. London: Routledge.

Spikins, Penny. 2015. How compassion made us human: the evolutionary origins of tenderness, trust and morality. Croydon: Pen \& Sword Archaeology.

Than, Ker. World's oldest cave art found-made by Neanderthals? June 14, 2012. National Geographic.

Trinkaus, Erik. 1983. The Shanidar Neanderthals. New York: Academic Press.

Valladas, H., N. Mercier, L. Froget, E. Hovers, J. L. Joron, W.H. Kimbel, and Y. Rak. 1999. TL dates for the Neanderthal site of the Amud Cave, Israel. Journal of Archaeological Science 26: 259-268.

Van Huyssteen, J. Wentzel. 2006. Alone in the world?. human uniqueness in science and theology. Grand Rapids, MI: William B. Eerdmans Publishing Company. 
Vermeersch, P.M., E. Paulissen, S. Stokes, C. Charlier, V. Van Peer, C. Stringer, and W. Lindsay. 1998. A middle Paleolithic burial of a modern human at Taramsa Hill, Egypt. Antiquity 72: 475-484. 